\title{
Chronic visceral acid sphingomyelinase deficiency (Niemann-Pick disease type B) in 16 Polish patients: long-term follow-up
}

Patryk Lipiński', Ladislav Kuchar², Ekaterina Y. Zakharova ${ }^{3}$, Galina V. Baydakova ${ }^{3}$, Agnieszka Ługowska ${ }^{4}$ and Anna Tylki-Szymańska ${ }^{1 *}$

\begin{abstract}
Background: Acid sphingomyelinase deficiency (ASMD), due to mutations in the sphingomyelin phosphodiesterase 1 (SMPD1) gene, is divided into infantile neurovisceral ASMD (Niemann-Pick type A), chronic neurovisceral ASMD (intermediate form, Niemann-Pick type A/B) and chronic visceral ASMD (Niemann-Pick type B).

We conducted a long-term observational, single-center study including 16 patients with chronic visceral ASMD.

Results: 12 patients were diagnosed in childhood and 4 others in adulthood, the oldest at the age of 50 . The mean time of follow-up was approximately 10 years (range: 6 months - 36 years). Splenomegaly was noted in all patients at diagnosis. Hepatomegaly was observed in $88 \%$ of patients. Moderately elevated (several-fold above the upper limit of normal values) serum transaminases were noted in $38 \%$ of patients. Cherry-red spots were found in five Gypsy children from one family and also in one adult Polish patient, a heterozygote for p.delR610 mutation. Dyslipidemia was noted in 50\% of patients. Interstitial lung disease was diagnosed in $44 \%$ of patients. Plasmatic lysosphingomyelin (SPC) was elevated in all the patients except one with p.V36A homozygosity and a very mild phenotype also presenting with elevated plasmatic SPC-509 but normal chitotriosidase activity. The most common variant of SMPD1 gene was p.G166R. We found a previously unreported variant in exon 2 (c.491G > T, p.G164 V) in one patient.
\end{abstract}

Conclusions: Chronic visceral ASMD could constitute a slowly progressing disease with a relatively good outcome. The combined measurement of lysosphingomyelin (SPC) and lysospingomyelin-509 (SPC-509) is an essential method for the assessment of ASMD course.

Keywords: Acid sphingomyelinase, Chronic visceral acid sphingomyelinase deficiency, Hepatosplenomegaly, Chitotriosidase, Lysosphingomyelin, Lysosphingomyelin-509

\section{Introduction}

Acid sphingomyelinase deficiency (ASMD), due to mutations in the sphingomyelin phosphodiesterase 1 (SMPD1) gene, was historically divided into two phenotypes: Niemann-Pick disease type A (OMIM 257200) - a neuronopathic, rapidly progressing and fatal disorder, and Niemann-Pick disease type B (OMIM 607616) - a non-neuronopathic, slowly progressive, visceral disorder $[1,2]$. An intermediate neurologic

\footnotetext{
* Correspondence: a.tylki@ipczd.pl

'Department of Pediatrics, Nutrition and Metabolic Diseases, The Children's

Memorial Health Institute, Warsaw, Poland

Full list of author information is available at the end of the article
}

phenotype, Niemann-Pick disease type A/B, was also reported in the literature $[3,4]$.

Recently, novel terminology for ASMD phenotypes was proposed including the following: infantile neurovisceral ASMD (Niemann-Pick type A), chronic neurovisceral ASMD (intermediate form, Niemann-Pick type A/B) and chronic visceral ASMD (Niemann-Pick type B) [5].

So far, only few longitudinal observational studies on ASMD have been published. However, the natural history of chronic visceral ASMD has not been exhaustively described yet due to a broad clinical heterogeneity and the lack of long-term follow-up of the patients [6-9].

(c) The Author(s). 2019 Open Access This article is distributed under the terms of the Creative Commons Attribution 4.0 International License (http://creativecommons.org/licenses/by/4.0/), which permits unrestricted use, distribution, and reproduction in any medium, provided you give appropriate credit to the original author(s) and the source, provide a link to the Creative Commons license, and indicate if changes were made. The Creative Commons Public Domain Dedication waiver (http://creativecommons.org/publicdomain/zero/1.0/) applies to the data made available in this article, unless otherwise stated. 
The aim of this study was to present long-term follow-up of chronic visceral ASMD patients concerning the clinical, biochemical and molecular findings. The usefulness of plasma biomarkers: lysosphingomyelin (SPC) and lysosphingomyelin-509 (SPC-509) was also presented.

\section{Patients and methods}

\section{Patients}

The article presents a long-term observational, single-center study of patients with chronic visceral ASMD. 16 patients who were diagnosed and followed-up at the Children's Memorial Health Institute (Warsaw, Poland) were enrolled into the study.

\section{Methods}

The chart review of patients' medical records concerning the demographics, the first presented signs and symptoms, age at diagnosis, as well as biochemical (acid sphingomyelinase activity in leukocytes, cultured skin fibroblasts or dried blood spot, serum chitotriosidase activity, lysosphingomyelin (SPC) and lysosphingomyelin-509 (SPC-509) levels in plasma, and also aspartate (AST) and alanine (ALT) aminotransferases, platelet count (PLT), total serum cholesterol (TC), high-density lipoprotein-cholesterol (HDL-C), low-density lipoprotein-cholesterol (LDL-C), triglycerides (TG), and molecular data (SMPD1 gene mutations) were collected. Data on pulmonary function included spirometry and imaging of the lungs (X-ray or CT-scan). Hepatosplenomegaly was assessed with imaging (ultrasound or CT-scan).

Ethical approval was obtained from the Children's Memorial Health Institute Bioethical Committee, Warsaw, Poland.

\section{Laboratory analyses}

The diagnosis of ASMD was confirmed by the demonstration of reduced ASM activity in peripheral blood leukocytes or cultured skin fibroblasts. In one patient, only a dried blood spot was available. ASM activity in leukocytes was measured with the 2-N-hexadecanoylamino-4-nitrophenylphosphorylcholine as a substrate [10]. As regards patients in whom ASM activity in leukocytes was inconclusive the second measurement in cultured skin fibroblasts was performed. Chitotriosidase activity was measured in plasma samples with a spectrofluorometric method as presented by Hollak et al. [11]. In cases suggestive of chitotriosidase deficiency, screening for the $24 \mathrm{bp}$-duplication was performed. The methodological details of plasmatic SPC and SPC-509 quantitation were characterized previously in a paper by Kuchar et al. [12]. Sequence analysis of the SMPD1 gene was performed either by targeted analysis of common mutations or whole gene sequencing. All identified molecular variants were prioritized according to the predicted effect on the protein.

Individual patients' characteristics are summarized in Table 1.

\section{Results}

Patients - demographics

A total of 16 patients ( 9 males, 7 females) were enrolled into the study. 6 patients from one family were of Gypsy ancestry and the others were of Polish origin.

Twelve patients were diagnosed in childhood (age range: 1 year - 14 years) and 4 others in adulthood, the oldest one at the age of 50 years. The mean age at diagnosis was 20 years and the median was 12 years. 4 patients were diagnosed through family screening in early childhood.

Presentation at diagnosis - Hepatosplenomegaly, serum transaminases and hematological parameters

Splenomegaly was noted in all the patients; two of them (Pt $8,10)$ were splenectomized because of thrombocytopenia at the age of 5 and 48 years, respectively. The presence of lipid-laden macrophages in histopathological examination prompted the final ASMD diagnosis.

Hepatomegaly was observed in 14 (88\%) out of 16 patients. All the patients had presented with a mild enlargement of the liver and spleen.

Elevated serum transaminases (several-fold above the upper limit of normal values) were noted in 6 (38\%) out of 16 patients.

Apart from two splenectomized patients, one patient (Pt 9) had initially presented with thrombocytopenia.

Cholestatic jaundice was noted in 2 (13\%) out of 16 patients. Those patients (Pt 1-2) also presented with coagulopathy (prolonged INR).

\section{Presentation at diagnosis - Biochemical analysis}

Data on ASM activity were available for 14 out of 16 patients ( 9 in peripheral blood leukocytes, 4 in skin fibroblasts and 1 in dried blood spot). In case of 2 other patients the diagnosis was established only by molecular analysis of the SMPD1 gene.

At the time of diagnosis, the chitotriosidase activity in plasma was available for 12 out of 16 patients. The mean level was $826 \mathrm{nmol} / \mathrm{ml} / \mathrm{hr}$. and it ranged from 40 to $3720 \mathrm{nmol} / \mathrm{ml} / \mathrm{hr}$. with the median at $236 \mathrm{nmol} / \mathrm{ml} / \mathrm{hr}$; with the reference range up to $150 \mathrm{nmol} / \mathrm{ml} / \mathrm{hr}$. Chitotriosidase activity was strongly correlated with the volume of the liver and spleen. One patient (Pt 8) was diagnosed with chitotriosidase deficiency - homozygote for the $24 \mathrm{bp}$-duplication in the CHIT1 gene.

\section{Molecular analysis}

Eleven various SMPD1 gene variants were identified in the study with 10 of them previously described in the 


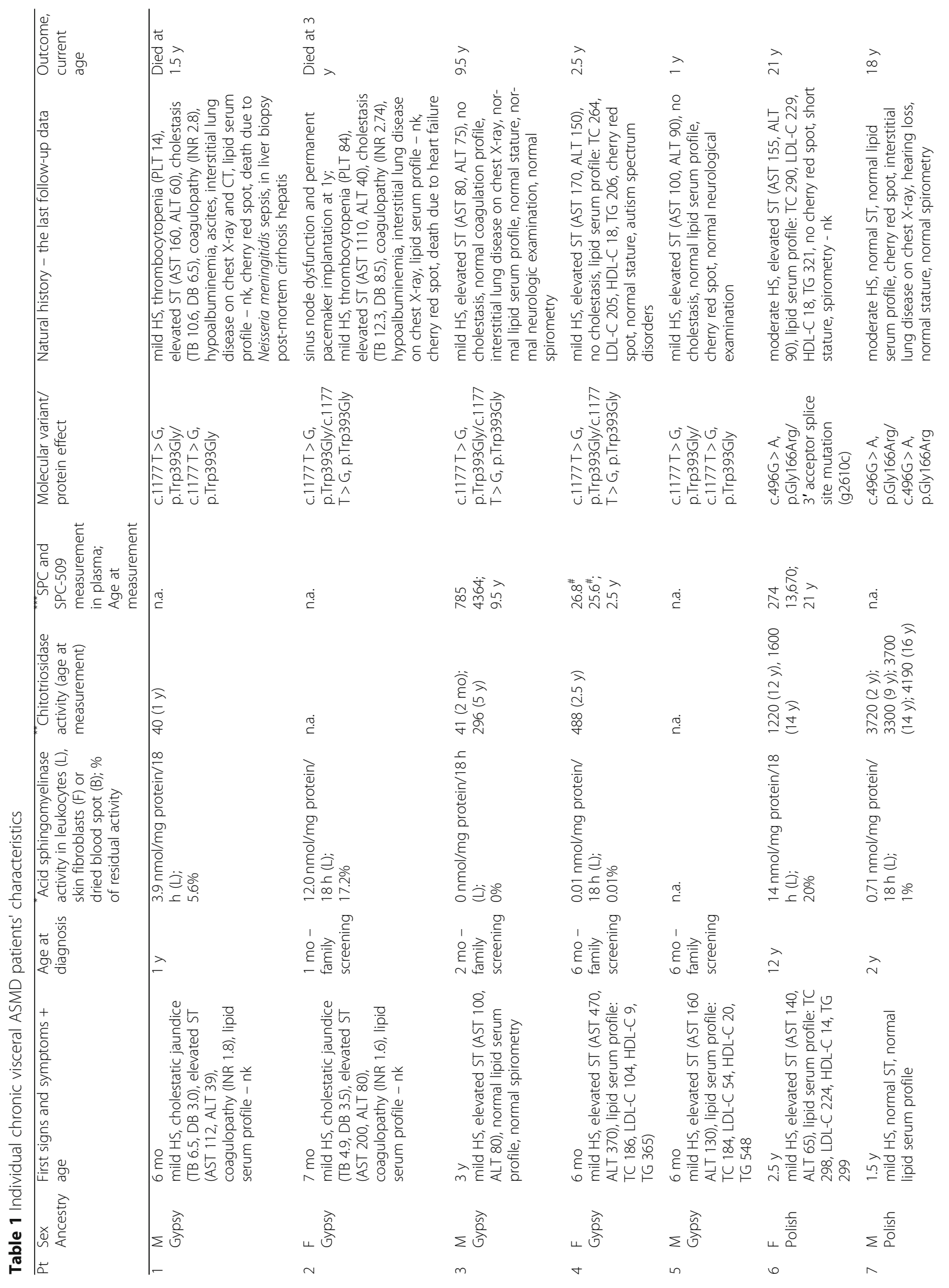




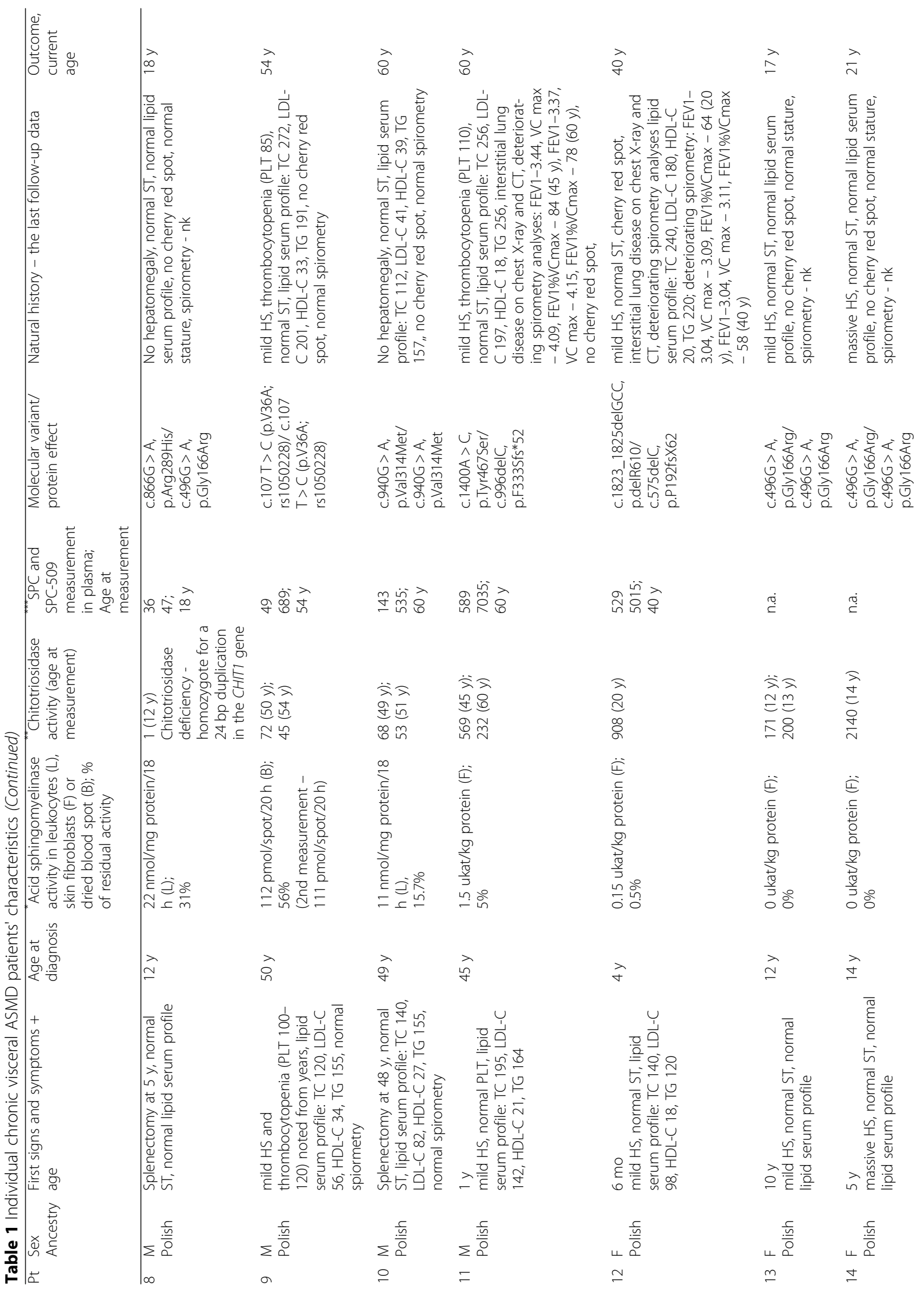




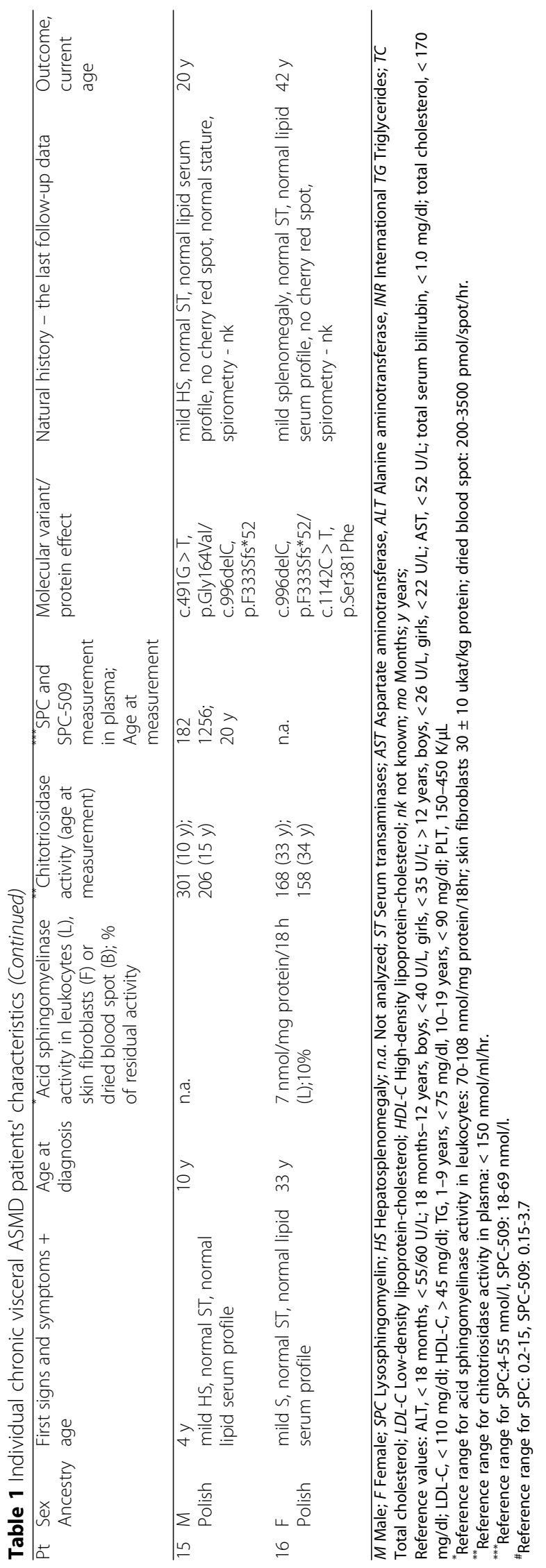


literature. In one patient (Pt 15) we found a previously unreported heterozygous variant in exon 2 (c.491G > T, p.G164 V) which is located in highly conserved nucleotides and moderately conserved amino acids positions with moderate physicochemical differences between the amino acids glycine and valine.

Missense mutations were the most common types of genetic lesions, comprising $75 \%$ of all alleles. The most common mutation was p.G166R comprising $25 \%$ of alleles. It was found in homozygosity in three patients and in heterozygosity in three others. This cohort contained only one patient, a heterozygote for p.delR610 mutation. One patient ( $\mathrm{Pt}$ 12) was identified as a homozygote for p.V36A variant, which was referred to as a non-synonymous single nucleotide polymorphism by Rhein et al. [13].

\section{Follow-up}

The mean time of follow-up in our study was approximately 10 years (range: 6 months -36 years).

\section{Follow-up - Hepatosplenomegaly, serum transaminases, hematological parameters and biochemical analysis}

The liver and spleen volume was stable during the follow-up.

Elevated serum transaminases observed in 6 patients at diagnosis remained comparable during the follow-up. Rising serum bilirubin levels and deterioration in liver synthetic function - hypoalbuminemia, coagulopathy (prolonged INR), were observed in 2 patients (Pt 1-2) who, at the time of diagnosis, presented with hepatosplenomegaly and cholestasis. They died at the age of 1.5 and 3 years, respectively, due to problems not related to liver disease (see Table 1).

Two patients who had undergone splenectomy were excluded from the analysis of the hematological parameters, because the abnormalities were related to hypersplenism. Over time, platelets tended to decrease in 3 patients and remained stable in other patients. At the last follow-up, thrombocytopenia was noted in 4 (28\%) out of 14 patients.

At the last follow-up (years 2017-18), the result of chitotriosidase activity in plasma was available for 9 patients, it decreased in 5 of them and slowly increased in 4 others. SPC and SPC-509 levels in plasma were assessed in 9 out of 16 patients at the last follow-up. In comparison to controls, SPC was elevated in 7 (78\%) patients, while in 2 patients only a slight elevation (Pt 10, 15) was observed. SPC-509 was elevated in 8 (89\%) out of 9 patients.

\section{Cholesterol and cardiovascular assessment at diagnosis and follow-up}

Data on lipid serum profile were available in 14 out of 16 patients at the time of diagnosis. They were completely normal in 7 (50\%) patients. In 7 (50\%) other persons lipid serum profile abnormalities were defined as follows: elevated TC (6/7), elevated LDL-C (3/7), elevated TG (7/7), decreased HDL-C (7/7).

A the last follow-up visit, data on lipid serum profile were completely normal in 8 patients - they had normalized in 1 patient (Pt 5). In 6 other patients, lipid serum profile abnormalities were defined as follows: elevated TC (5/6), elevated LDL-C (5/6), elevated TG (6/6), decreased HDL-C (6/6).

\section{Pulmonary assessment at diagnosis and follow-up}

Chest radiography and CT-scanning were used to diagnose interstitial lung disease in $5(31 \%)$ patients out of the whole cohort. Data on pulmonary function tests (spirometry analyses) were available in all of them with a mild obstructive disease found in 2 out of 5 patients (Pt 11-12). During the follow-up, an insignificant deterioration of these parameters was observed.

DLCO parameters were not analysed in the study.

\section{Neurological assessment and ophthalmological findings} Cherry-red spots were reported in 5 Gypsy children from one family (Pt 1-5) and 1 Polish adult patient (Pt 12). All of them presented with the absence of neurological impairment during long-term follow-up.

\section{Growth parameters}

Only 1 (13\%) out of 8 children in the study had a short stature which was assigned as a familial short stature.

\section{Discussion}

In the study we described genotypic and phenotypic characteristics of 16 patients from Poland with chronic visceral ASMD. Long-term follow-up results were characterised of this group of patients.

ASMD has a predominant expression in the liver and spleen due to the accumulation of sphingomyelin and other lipids in the macrophage-monocyte system and also hepatocytes [12, 14, 15]. All our patients had initially presented with splenomegaly and almost all of them with hepatomegaly. In some of the patients, the liver and spleen enlargement were diagnosed incidentally and had constituted the sole signs presenting for many years before the final ASMD diagnosis. Similarly, in the literature, hepatosplenomegaly is the most commonly reported clinical finding at the initial presentation of the disease [5-9].

Thus, an elevated serum chitotriosidase activity, which is specifically expressed by activated macrophages, could be noted [16-19].

Liver fibrosis and finally cirrhosis occur in the natural course of ASMD [5, 14, 15]. Therefore, elevated serum transaminases may be noted. On the basis of our 
observations, it is worth emphasizing that only a mild to moderate level of elevation is reported, reaching several-fold above the upper limit of normal values. Based on the obtained data, chronic visceral ASMD may also be a reason for impaired liver synthetic function. Serum bilirubin concentrations are commonly normal, except for children who could present with cholestatic liver disease [5].

The natural course of liver disease is usually non-progressive and it is comparable with data from other reports $[6-9,14-16,20]$. However, a subset of patients is described in the literature, who are at an increased risk for hepatic failure occurrence [21, 22]. Five Gypsy patients (Pt 1-5) from one family, affected with p.T393G missense mutation in a homozygous state, had presented with a variable disease course. Two of them (Pt 1-2) had cholestatic liver disease with coagulopathy which had progressed to chronic liver failure but they had finally succumbed due to reasons not related to liver disease (Neisseria meningitidis sepsis and heart failure, respectively). In 3 other patients the disease course was mild to moderate with stable liver disease. It shows that, apart from the genotype, other factors such as environmental ones may also contribute to disease severity patients 3-5 were under family foster care. Furthermore, there is 1 more child in this family, currently aged 5, who is healthy (normal ASM activity).

Several cases of adult ASMD patients with cirrhosis and portal hypertension were reported in the literature [16, 22, 23]. In our cohort, apart from 2 splenectomized patients, 3 other patients presented with signs of portal hypertension in the form of a mild thrombocytopenia (a feature of hypersplenism).

Macular cherry-red spots constitute the ophthalmologic finding caused by the accumulation of sphingomyelin in the retina. They were reported in the literature, both in neuronopathic and non-neuronopathic forms of ASMD [3-9, 24]. In our cohort, cherry-red spots were found in five Gypsy children from one family (Pt 1-5) and also in 1 adult Polish patient (Pt 10). None of the patients with macular cherry-red spots had presented with signs or symptoms of central nervous system involvement. Notably, some patients with chronic visceral ASMD could present with macular cherry-red spots.

Lipid abnormalities are characteristic for ASMD featured with an abnormal lipid profile in the serum showing increased levels of serum TC, LDL-C, TG and decreased levels of HDL-C $[1,2,6-9,20,24-26]$. The finding of dyslipidemia was reported in half of the patients from this cohort. The most frequent features included elevated TG levels and decreased HDL-C levels. These abnormalities might be associated with the development of atherosclerotic heart disease. Contrary to other reports in the literature, none of our adult patients presented with symptomatic atherosclerotic heart disease $[2,25]$.

About one third of patients in this study have a diagnosis of interstitial lung disease. The pathophysiology of the lung disease is associated with the infiltration of the alveolar septa, bronchial walls, and pleura by lipid-laden macrophages potentially leading to a progressively worsening restrictive pattern on pulmonary function testing $[6-9,27,28]$. Only slow and non-significant progression of pulmonary disease observed on the basis of pulmonary function tests was reported in our study group emphasizing controlled lung involvement in chronic visceral ASMD.

To date, about 200 pathogenic variants in the SMPD1 gene have been reported. SMPD1 gene mutations profile described in our study was similar to others in the literature where missense mutations constituted the most commonly reported ones [13, 29-33].

The most common variant in the study was a missense mutation p.G166R and it was found in 6 patients; in 3 of them in a homozygous state and in 3 others in a heterozygous state. Those patients were living in the same region, so we could hypothesize on a slight founder effect.

The molecular variant p.F333Sfs*52, which was found in heterozygosity in 2 patients (Pt 15,16 ) constitutes a common Ashkenazi Jewish type A mutation and is related to a severe phenotype of the disease [13, 29]. Based on our study, we could hypothesize about a protective character of the second mutation, p.G164 V and p.S381P, respectively, responsible for a mild phenotype of chronic visceral ASMD.

To better characterize the disease progress and genotype-phenotype correlation, we used two serum biomarkers, the deacylated form of sphingomyelin - lysosphingomyelin (SPC) and SPC analog - lysosphingomyelin-509 (SPC-509). 9 patients from the study group underwent SPC and SPC-509 measurement at the last follow-up visit. It was a single measurement as these biomarkers had the levels rising with time.

SPC was found to be a promising biomarker in ASMD and SPC-509 in both ASMD and Niemann-Pick disease type C [34-37]. In 2 study patients (Pt 8 and 9) SPC levels were found in a control range, so we could categorize them as a very mild phenotype. In Patient 8 , the second biomarker SCP-509, was also found in a control range. This patient was splenectomized in infancy, which put a new light on those two biomarkers suggesting that splenectomy may affect SPC and SCP-509 levels. Based on those observations, we propose to measure ASM activity in patients with normal SPC-509 who had undergone splenectomy.

Patient 9 was also found to have elevated SPC-509 levels and to be chitotriosidase-deficient. This patient was identified as a homozygote for a known SNP, 
p.V36A. The fact about normal SPC levels and elevated SPC-509 levels, suggests that the elevation of SPC509 only, should not exclude ASMD diagnosis in patients presenting with a mild phenotype. In such cases, we propose to measure ASM activity prior to SMPD1 gene mutation analyses.

In 1 patient with an elevated SPC (Pt 10), there was only a mild level of elevation. This patient was found to be a homozygote for p.G314Val mutation presenting with no history of disease up to adulthood, when he had undergone splenectomy. Based on the serum biomarkers levels and the long-term follow-up of this patient, we could correlate p.G314Val variant with a mild phenotype of ASMD.

\section{Conclusions}

In the group of chronic visceral ASM deficient patients, spleen enlargement was always present. Liver enlargement was observed in a majority of patients and was associated with moderately elevated serum transaminases.

Macular cherry-red spots were also noted in chronic visceral ASM deficient patients.

All the patients, apart from one (with familial short stature), presented with normal stature.

The combined measurement of lysosphingomyelin (SPC) and lysospingomyelin-509 (SPC-509) was a highly essential method for the assessment of ASMD course. Serum chitotriosidase activity was mostly conclusive in cases with clinically significant hepatosplenomegaly.

Chronic visceral ASMD could have a mild course with a relatively good outcome.

Other factors such as environmental ones could contribute to the disease severity.

\section{Abbreviations}

ASMD: acid sphingomyelinase deficiency; CT: computed tomography; HDLC: high-density lipoprotein-cholesterol; LDL-C: low-density lipoproteincholesterol; SMPD1 gene: sphingomyelin phosphodiesterase 1 gene; SPC: Iysosphingomyelin; SPC-509: Iysosphingomyelin-509; TC: total serum cholesterol; TG: triglycerides (TG)

\section{Acknowledgments}

None.

\section{Availability of data and supporting materials section}

All data generated or analysed during this study are included in this published article.

\section{Authors' contribution statement}

The specific contributions made by each author: a) Conception and design of study - PL, ATS, b) Acquisition of data - PL, LK, EYZ, GB, AL, ATS. C) Analysis and/or interpretation of data - PL, LK, EYZ, GB, AL, ATS. d) Drafting the manuscript - PL, ATS. e) Revising the manuscript critically for important intellectual content - LK, EYZ, AL, ATS. f) Approval of the version of the manuscript to be published - PL, LK, EYZ, GB, AL, ATS.

\section{Funding}

There were no funding sources.
Ethics approval and consent to participate

The study has been approved by an ethics committee of The Children's Memorial Health Institute in Warsaw.

Informed consent was obtained from all included patients.

\section{Consent for publication}

Not applicable.

\section{Competing interests}

All authors certify that they have NO affiliations with or involvement in any organization or entity with any financial or non-financial interest in the subject matter or materials discussed in this manuscript.

\section{Publisher's Note}

Springer Nature remains neutral with regard to jurisdictional claims in published maps and institutional affiliations.

\section{Author details}

'Department of Pediatrics, Nutrition and Metabolic Diseases, The Children's Memorial Health Institute, Warsaw, Poland. ${ }^{2}$ Institute of Inherited Metabolic Disorders, First Faculty of Medicine, Charles University and General University Hospital, Prague, Czech Republic. ${ }^{3}$ Department of Inherited Metabolic

Diseases, Research Center for Medical Genetics, Moscow, Russian Federation. ${ }^{4}$ Department of Genetics, Institute of Psychiatry and Neurology, Warsaw, Poland.

Received: 22 October 2018 Accepted: 10 February 2019

Published online: 22 February 2019

\section{References}

1. Schuchman EH, Desnick RJ. Types a and B Niemann-pick disease. Mol Genet Metab. 2017:120:27-33.

2. McGovern MM, Avetisyan R, Sanson BJ, Lidove O. Disease manifestations and burden of illness in patients with acid sphingomyelinase deficiency (ASMD). Orphanet J Rare Dis. 2017;12:41.

3. Pavlů-Pereira $\mathrm{H}$, Asfaw $\mathrm{B}$, Poupctová $\mathrm{H}$, et al. Acid sphingomyelinase deficiency. Phenotype variability with prevalence of intermediate phenotype in a series of twenty-five Czech and Slovak patients. A multi-approach study. J Inherit Metab Dis. 2005;28:203-27.

4. Wasserstein MP, Aron A, Brodie SE, Simonaro C, Desnick RJ, McGovern MM. Acid sphingomyelinase deficiency: prevalence and characterization of an intermediate phenotype of Niemann-pick disease. J Pediatr. 2006;149:554-9.

5. McGovern MM, Dionisi-Vici C, Giugliani R, Hwu P, Lidove O, Lukacs Z, Eugen Mengel K, Mistry PK, Schuchman EH, Wasserstein MP. Consensus recommendation for a diagnostic guideline for acid sphingomyelinase deficiency. Genet Med. 2017;19:967-74.

6. McGovern MM, Wasserstein MP, Giugliani R, et al. A prospective, crosssectional survey study of the natural history of Niemann-pick disease type B. Pediatrics. 2008;122:e341-9.

7. Wasserstein MP, Desnick RJ, Schuchman EH, et al. The natural history of type B Niemann-pick disease: results from a 10-year longitudinal study. Pediatrics. 2004;114:e672-7.

8. Hollak CE, de Sonnaville ES, Cassiman D, et al. Acid sphingomyelinase (Asm) deficiency patients in the Netherlands and Belgium: disease spectrum and natural course in attenuated patients. Mol Genet Metab. 2012;107:526-33.

9. Lidove O, Belmatoug N, Froissart R, Lavigne C, Durieu I, Mazodier K, Serratrice C, Douillard C, Goizet C, Cathebras P, Besson G, Amoura Z, Tazi A, Gatfossé M, Rivière S, Sené T, Vanier MT, Ziza JM. Acid sphingomyelinase deficiency (Niemann-pick disease type B) in adulthood: a retrospective multicentric study of 28 adult cases. Rev Med Interne. 2017;38:291-9.

10. Gal AE, Fash FJ. Synthesis of 2-n-(hexadecanoyl)-amino-4-nitrophenyl phosphorylcholine-hydroxide, a chromogenic substrate for assaying sphingomyelinase activity. Chem Phys Lipids 1976;161:71-79.

11. Hollak CE, van Weely S, van Oers MH, Aerts JM. Marked elevation of plasma chitotriosidase activity. A novel hallmark of Gaucher disease. J Clin Invest. 1994;93:1288-92.

12. Kuchar L, Sikora J, Gulinello ME, Poupetova H, Lugowska A, Malinova V Jahnova H, Asfaw B, Ledvinova J. Quantitation of plasmatic lysosphingomyelin and lysosphingomyelin-509 for differential screening of Niemann-pick a/B and C diseases. Anal Biochem. 2017;525:73-7. 
13. Rhein C, Mühle C, Kornhuber J, Reichel M. Alleged detrimental mutations in the SMPD1 gene in patients with Niemann-pick disease. Int J Mol Sci. 2015; 16:13649-52.

14. McGovern MM, Lippa N, Bagiella E, Schuchman EH, Desnick RJ, Wasserstein MP. Morbidity and mortality in type B Niemann-pick disease. Genet Med. 2013;15:618-23.

15. Cassiman D, Packman S, Bembi B, et al. Cause of death in patients with chronic visceral and chronic neurovisceral acid sphingomyelinase deficiency (Niemann-pick disease type B and B variant): literature review and report of new cases. Mol Genet Metab. 2016;118:206-13.

16. Thurberg BL, Wasserstein MP, Schiano T, O'Brien F. Liver and skin histopathology in adults with acid sphingomyelinase deficiency (Niemann-pick disease type B). Am J Surg Pathol. 2012;36:1234-46.

17. Sheth JJ, Sheth FJ, Oza NJ, Gambhir PS, Dave UP, Shah RC. Plasma chitotriosidase activity in children with lysosomal storage disorders. Indian J Pediatr. 2010;77:203-5.

18. Kadali S, Kolusu A, Sunkara S, Gummadi MR, Undamatla J. Clinical evaluation of chitotriosidase enzyme activity in Gaucher and Niemann pick a/B diseases: a retrospective study from India. Clin Chim Acta. 2016:457:8-11.

19. Brinkman J, Wijburg FA, Hollak CE, et al. Plasma chitotriosidase and CCL18 early biochemical surrogate markers in type B Niemann-pick disease. J Inherit Metab Dis. 2005;28:13-20.

20. Cox GF, Clarke LA, Giugliani R, McGovern MM. Burden of illness in acid sphingomyelinase deficiency: a retrospective chart review of 100 patients. JIMD Rep. 2018. https://doi.org/10.1007/8904_2018_120.

21. Labrune $P$, Bedossa $P$, Huguet $P$, Roset $F$, Vanier MT, Odievre M. Fatal liver failure in two children with Niemann-pick disease type B. J Pediatr Gastroenterol Nutr. 1991;13:104-9.

22. Acuña M, Martínez $P$, Moraga $C$, He X, Moraga M, Hunter B, Nuernberg $P$, Gutiérrez RA, González M, Schuchman EH, Santos JL, Miquel JF, Mabe P, Zanlungo S. Epidemiological, clinical and biochemical characterization of the p.(Ala359Asp) SMPD1 variant causing Niemann-pick disease type B. Eur J Hum Genet. 2016;24:208-13.

23. Tassoni JP Jr, Fawaz KA, Johnston DE. Cirrhosis and portal hypertension in a patient with adult Niemann-pick disease. Gastroenterology. 1991;100:567-9.

24. McGovern MM, Wasserstein MP, Aron A, Desnick RJ, Schuchman EH, Brodie SE. Ocular manifestations of Niemann-pick disease type B. Ophthalmology. 2004;111:1424-7.

25. McGovern MM, Pohl-Worgall T, Deckelbaum RJ, et al. Lipid abnormalities in children with types a and B Niemann pick disease. J Pediatr. 2004;145:77-81.

26. Lee $C Y$, Krimbou L, Vincent J. Compound heterozygosity at the sphingomyelin phosphodiesterase-1 (SMPD1) gene is associated with low HDL cholesterol. Hum Genet. 2003;12:552-62.

27. Mendelson DS, Wasserstein MP, Desnick RJ, et al. Type B Niemann-pick disease: findings at chest radiography, thin-section $C T$, and pulmonary function testing. Radiology. 2006;238:339-45.

28. Nicholson AG, Florio R, Hansell DM, et al. Pulmonary involvement by Niemannpick disease. A report of six cases. Histopathology. 2006;48:596-603.

29. Zampieri S, Filocamo M, Pianta A, et al. SMPD1 mutation update: database and comprehensive analysis of published and novel variants. Hum Mutat. 2016;37:139-47.

30. Simonaro CM, Desnick RJ, McGovern MM, Wasserstein MP, Schuchman EH The demographics and distribution of type B Niemann-pick disease: novel mutations lead to new genotype/phenotype correlations. Am J Hum Genet. 2002;71:1413-9

31. Mihaylova V, Hantke J, Sinigerska I, et al. Highly variable neural involvement in sphingomyelinase-deficient Niemann-pick disease caused by an ancestral gypsy mutation. Brain. 2007;130(Pt 4):1050-61.

32. Desnick JP, Kim J, He X, Wasserstein MP, Simonaro CM, Identification SEH. Characterization of eight novel SMPD1 mutations causing types a and B Niemann-pick disease. Mol Med. 2010;16:316-21.

33. Zhang H, Wang Y, Gong Z, Li X, Qiu W, Han L, Ye J, Gu X. Identification of a distinct mutation spectrum in the SMPD1 gene of Chinese patients with acid sphingomyelinase-deficient Niemann-pick disease. Orphanet J Rare Dis. 2013;8:15.

34. Chuang WL, Pacheco J, Cooper S, et al. Lyso-sphingomyelin is elevated in dried blood spots of Niemann-pick B patients. Mol Genet Metab. 2014;111: 209-11.

35. Voorink-Moret M, Goorden SMI, van Kuilenburg ABP, Wijburg FA, Ghauharali-van der Vlugt JMM, Beers-Stet FS, Zoetekouw A, Kulik W, Hollak
CEM, Vaz FM. Rapid screening for lipid storage disorders using biochemical markers. Expert center data and review of the literature. Mol Genet Metab. 2018;123:76-84

36. WelforRW GM, Lourenco CM, Mengel E, Marquardt T, Reunert J, Amraoui $Y$, Kolb SA, Morand O, Groenen P. Plasma lysosphingomyelin demonstrates great potential as a diagnostic biomarker for Niemann-pick disease type C in a retrospective study. PLoS One. 2014;9:e114669.

37. Giese AK, Mascher H, Grittner U, Eichler S, Kramp G, Lukas J, Vruchte D, Al Eisa N, Cortina-Borja M, Porter FD, Platt FM, Rolfs A. A novel, highly sensitive and specific biomarker for Niemann-pick type C1 disease. Orphanet J Rare Dis. 2015:10:78.
Ready to submit your research? Choose BMC and benefit from:

- fast, convenient online submission

- thorough peer review by experienced researchers in your field

- rapid publication on acceptance

- support for research data, including large and complex data types

- gold Open Access which fosters wider collaboration and increased citations

- maximum visibility for your research: over $100 \mathrm{M}$ website views per year

At $\mathrm{BMC}$, research is always in progress.

Learn more biomedcentral.com/submissions 